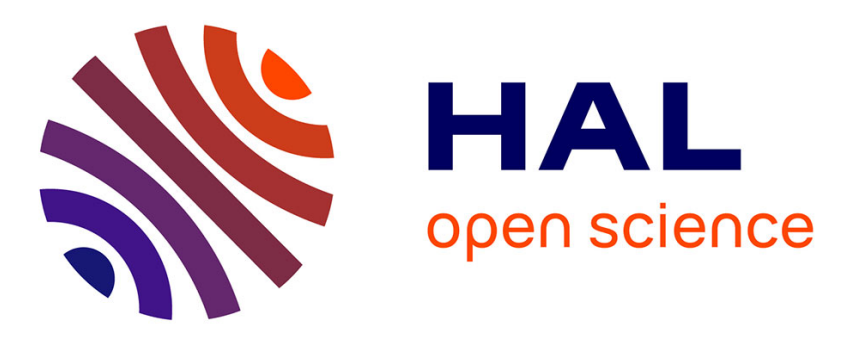

\title{
Monetary and budgetary-fiscal policy interactions in a Keynesian context: revisiting macroeconomic governance
}

Angel Asensio

\section{- To cite this version:}

Angel Asensio. Monetary and budgetary-fiscal policy interactions in a Keynesian context: revisiting macroeconomic governance. Macroeconomics and macroeconomic policies - alternatives to the orthodoxy, 9th workshop of the research network Alternative Macroeconomic Policies, Oct 2005, Berlin, Germany. halshs-00139029

\section{HAL Id: halshs-00139029 \\ https://shs.hal.science/halshs-00139029}

Submitted on 28 Mar 2007

HAL is a multi-disciplinary open access archive for the deposit and dissemination of scientific research documents, whether they are published or not. The documents may come from teaching and research institutions in France or abroad, or from public or private research centers.
L'archive ouverte pluridisciplinaire HAL, est destinée au dépôt et à la diffusion de documents scientifiques de niveau recherche, publiés ou non, émanant des établissements d'enseignement et de recherche français ou étrangers, des laboratoires publics ou privés. 
Monetary and budgetary-fiscal policy interactions in a Keynesian context: revisiting macroeconomic governance

Angel Asensio, CEPN, Université Paris 13 - CNRS

March 2006

Abstract

Because it was designed for efficient stationary regimes, the New-Consensus Macroeconomic governance carries several drawbacks when implemented in Keynesian non-ergodic regimes. As long as Keynesian unemployment is interpreted in terms of 'natural' rate, it serves as a macroeconomic policy target in such a way that the policy mix may anchor the system far from full employment. We develop an argument that suggests a Keynesian explanation (which involves inappropriate economic policy) of what New Keynesians have referred to as unemployment hysteresis. However, difficulties do not vanish when authorities adopt the Keynesian vision of the world, for policy makers also have to deal with uncertainty. In contrast with the automatic economic-policy rules of the New Consensus Macroeconomics (NCM), we put forward a Keynesian pragmatic and progressive approach, based on intermediate targets designed with respect to the confidence that authorities have in the chances of success (which depends on the context and moves with it). Monetary and budgetary-fiscal policy interactions are discussed in such a context. Even if the monetary policy ability to reduce interest rates and increase effective demand is doubtful, it matters indirectly through avoiding increases in interest rates when fiscal and budgetary policy aims to stimulate effective demand. 


\section{Introduction}

According to the New Consensus Macroeconomics (NCM), economic policy deals with different problems depending on the length of the period considered.

If the period is long enough, competitive forces drive the rate of unemployment to the 'natural level'. Theoretically, a succession of such periods should not exhibit statistical evidence of unemployment pressure on wages or consumer prices; the Phillips relation should look vertical. In each of these 'long periods', expected prices variations equal the effective values, and contracts are negotiated in accordance with the right expectations. That is the reason why systematic (hence expected) stimulations of aggregate demand ${ }^{1}$ do not reduce real wages and unemployment; they only strengthen inflation.

By contrast, in Keynesian effective-demand led systems, it is doubtful that market forces spontaneously guide the system towards a natural equilibrium in the long run. Equilibrium is embedded in a changing and uncertain context which makes expectations a poor device for decision making because there is no predictable trend or trajectory. Keynesian analysis breaks with the idea that expectations tend to be right when the length of the periods is extended. It breaks also with the idea that, over the defined 'long periods', contracts are negotiated on the basis of right expectations. The 'long run' which is required for the Phillips curve to be vertical simply makes no sense in such a context.

The breakdown between the two approaches is less evident in the short run since they agree on the positive impact of aggregate demand policies. Let us summarize the NCM argument. Because the adjustment of wages to the state of affairs takes more time, an inverse relation between the rate of variation in wages and the magnitude of the deviation from the natural rate of unemployment can be observed. 
Inflation plays a decisive role here (provided it has not been expected) because it reduces the real wages, and makes it acceptable for firms to respond to an increase in demand for goods and services.

In a recent post-Keynesian perspective, Kriesler \& Lavoie [2005], following Freedman, Harcourt \& Kriesler [2004] and Palacio-Vera [2002], suggested that capacity utilization only influences inflation when its level is very low or when there is full capacity utilization. Making such an assumption within a standard NCM model, which encompasses an IS demand function and a monetary reaction function à la Taylor, implies that for a large range of capacity utilization, the monetary policy influences the rate of capacity utilization, not inflation. In this case, excess of productive capacity makes it possible for firms to increase production and employment in response to an increasing effective demand without having to pay more attractive nominal wages, and without need for lowering the real cost of labour through inflation. Notice that the contrast with the NCM fades if one makes the reasonable assumption that inflationary pressures begins before the full capacity utilization is reached ${ }^{2}$.

Following these considerations one could think that Keynesians agree with the new consensus as far as short run economic behaviour is considered. But this idea is wrong, since the 'short period' makes no sense except with reference to the 'long period' of the NCM. 'Short periods' only reveal deviations from the 'long run' equilibrium path, accidents that markets forces will correct even without the help of economic policy. On the contrary, in a Keynesian world, equilibrium never is a temporary anomaly; it is a stable solution of the economic system, which is more or less distant from full employment depending on the level of effective demand, and which moves according to it. 
Such a disagreement about the nature of the economic equilibrium had to deliver diverging assessments of economic policy. While the ones see a simple smoothing device devoted to stabilize the system around a presumed natural trajectory ${ }^{3}$, the others deal with a wandering system whose evolution, never known in advance, depends on the support given by public policies. For the ones, inflation is the consequence of abusive stabilization policies, especially monetary policy ${ }^{4}$; they recommend strong restrictions to the instruments. For the others, inflation results from the conflicting distribution of national income. To tighten monetary policy in such a context would be inaccurate and could provoke a depression, or make it more serious. In addition, the supremacy the NCM grants to monetary over fiscal policy contrasts with the pitfalls that Keynes identified with respect to the control of the rates of interest, and their influence on effective demand and inflation. It contrasts also with the role of budgetary and fiscal policy in the Keynesian literature ${ }^{5}$.

The paper aims to extend the reflection on Keynesian alternative for macroeconomic governance. It focuses on the connection between monetary and fiscal policy in front of the triple problem of controlling inflation, public finance and employment. It sheds a new light on monetary policy through analyzing complementarities with respect to budgetary and fiscal policy, and through the study of interactions between the policy mix and the distributive conflict.

Section 2 compares the equilibrium main properties of the two theoretical frameworks. The functional interdependences among the different markets are examined methodically (goods, labour, bonds, money). We show that, despite the formal similarity of the system-behaviour modelling around equilibrium, there are strong differences in the conclusions which can be drawn from the two approaches. The reason is of course that the definitions of variables and parameters differ, as well 
as the adjustment process and properties of the equilibrium. Section 3 focuses on the implications of such differences for the study of monetary and budgetary-fiscal policies interactions and complementarities in a Keynesian context.

2. General equilibrium alternative theories

We start with a simple linear model which aims to study the effects of the two types of governance in the short run ${ }^{6}$. Variables are expressed in terms of relative variations from their initial value, excepting the rate of interest and the tax rate, which are expressed as variations. First the NCM will be analysed in terms of general equilibrium. Then, the main Keynesian differences will be put forward from the same general equilibrium perspective.

\subsection{General equilibrium modelling in presumed stationary regimes}

The usual Walrasian macroeconomics is modelled at first, so as to extend the framework towards NCM.

\subsubsection{Macroeconomics in Walrasian terms}

We consider for the moment a three-market structure (goods, labour and bonds) with two relative prices (the real wage and the rate of interest) ${ }^{7}$. However, because of the Walras law, the equilibrium condition for the market of bonds will remain implicit.

\section{Labour market}

At equilibrium, variations in real wages and employment compensate for the marginal disutility of labour (supply side) and furthermore insure profit 
maximisation (demand side). The marginal productivity equalization to the real cost of labour induces a decreasing relation between employment and real wage:

$n=-\rho \omega+d$

$n$ is the relative variation in employment

$\omega$ is the relative variation in real wage (that is the quantity of goods paid in exchange of the labour unit)

On the other hand, equalization of the marginal disutility of labour to the real wage means an increasing relation. It will be useful to reverse this relation in order to express the real wage as a function of the level of employment given by equation (1): $\omega=\theta n$

In a monetary economy, equation (2) would suppose the nominal wage variation (w) to depend on both the price index variation over the period ( $p$, see below about the nominal price index determination in the model with money), and the additional labour employed if necessary:

$w=p+\theta n$

These two equations insure that firms remain on their demand for labour curve, and that workers remain on their supply curve at equilibrium.

\section{Market for goods}

The supply of goods depends on the quantity of inputs, especially labour in the short run, and therefore technology will be represented as:

$y=\alpha n+c$

$y$ is the relative variation in the quantity of output and $c$ represents other exogenous technological factors. We assume $\alpha<1$ (diminishing marginal product of labour). 
Equations (1) to (3) give relative variations in production, employment and real wages as functions of the structural parameters and exogenous variables of the model:

$$
\begin{aligned}
& n=\frac{d}{1+\rho \theta} \\
& y=\alpha \frac{d}{1+\rho \theta}+c \\
& \omega=\theta \frac{d}{1+\rho \theta}
\end{aligned}
$$

Hence, economic activity depends only on technology and labour market conditions. The rate of interest insures aggregate demand for any additional production. Since the market equilibrium requires equal supply and demand ${ }^{8}$ :

$$
y=-\sigma \hat{i}+\lambda(\varphi g+a)-\gamma \hat{t}
$$

$g$ : relative variation in the government demand for goods

$\hat{t}$ : variation in the tax rate

$a$ : relative variation in the exogenous part of aggregate private demand

$\hat{i}$ : variation in the rate of interest

nb $\varphi$ is the initial tax rate

we get:

$\hat{i}=-\frac{1}{\sigma} c-\frac{\gamma}{\sigma} \hat{t}+\frac{\lambda}{\sigma}(\varphi g+a)-\frac{\alpha}{\sigma(1+\rho \theta)} d$

This rate of interest is both the clearing market condition for bonds and, through equalization of saving and investment, the condition for the aggregate demand of goods to be equal to the aggregate supply. Notice that the tax rate, government expenditures and other aggregate demand components do not influence the 
production and employment levels at equilibrium; their variations only produce crowding out effects through the adjustment of the interest rate.

\section{Market for money}

In this theoretic framework, money is only a transaction device, and demand for money varies following the volume and price of transactions. Assuming a constant money circulation velocity, the equilibrium condition requires any variation in the quantity of money ( $m$, exogenous for the moment) to be offset by an equivalent variation in the demand for money:

$m=y+p$

As far as the demand for real money balances depends on real income, it depends on technology and labour market conditions; hence inflation results from excessive real money balances relative to the need for real money balances (at the previous prices):

$p=m-c-\alpha \frac{d}{1+\rho \theta}$

Other things being equal ( $c=d=0$ ), prices vary in proportion to the money supply, without any effect on real variables and relative prices (including the rate of interest).

\section{Macroeconomic policy}

For the reason we have just mentioned, the sole valid goal that monetary policy may target concerns inflation control. On the other hand, budgetary and fiscal policy is not necessary for stabilization purposes as far as markets are supposed to work 'perfectly'. It may however produce temporary or permanent effects on relative prices and real variables because of distortions on the resources allocation process. This 
view put traditionally the economic efficiency in conflict with the fiscal redistributive laws on which the social order is based.

\subsubsection{The new synthesis}

After Keynes had demonstrated the decisive importance of expectations for macroeconomic analysis, the rational expectation hypothesis gave a new impulse to (Neo)classical economics during the seventies. It was shown that in stochastic stationary regimes, the main properties of the classical system continued to work provided that market efficiency was postulated. 'New Keynesian Economics' share most of this revitalized New Classical framework, even though it put forward nominal and real rigidities, which prevent the competitive process to work perfectly in the 'short run'. If nominal wages, for example, are imperfectly flexible, inflationary shocks temporarily move real wages and employment from their natural level. Demand policies may be useful in this case, but only to the extent that they use the surprise-inflation channel. Yet, if money can influence relative prices and other real variables temporary, it plays a limited role in New Keynesian Macroeconomics because rational expectations make it possible to predict future values of variables without systematic errors. Hence, as far as stochastic shocks only produce temporary deviations in presumed stationary regimes ${ }^{9}$, the 'long run' behaviour of the system is basically the same as the neoclassical one.

\section{Labour market}

Using monetary prices and wages, the demand for labour may be rewritten:

$$
n=\rho(p-w)+d
$$


It is possible to introduce fiscal distortion effects by supposing that in the short run they work through the price of the variable input: replacing the nominal cost of labour $(W)$ by $W(1+\xi t)$, where $0 \leq \xi<1$ measures the (weakened) impact of the tax rate on the labour cost, profit maximisation requires $\partial Y / \partial N=W(1+\xi t) / P$. The demand for labour relative variation $(n)$ then takes the form of a function of the fiscallycorrected labour cost, which relative variation can be approximated by $(p-w-\xi \hat{t})$ for small values of $\hat{t}$ :

$n=\rho(p-w-\xi \hat{t})+d$

We will suppose that labour contracts have been negotiated, at the starting point of the period, on the basis of the expected rate of inflation for the current period $\left(p^{a}\right)$ :

$w-p^{a}=\theta n$

From (1') we get:

$w=p+\frac{\theta d-\left(p-p^{a}\right)-\rho \theta \xi \hat{t}}{1+\rho \theta}$

$n=\frac{d+\rho\left(p-p^{a}\right)-\rho \xi \hat{t}}{1+\rho \theta}$

Hence, if $p^{a}=p$ (which is assumed to be true in the 'long run', as a result of rational expectations in stationary regimes), employment and production are the same as in the previous model (forgetting the fiscal distortion effect), but in case of inflationary surprise $\left(p \neq p^{a}\right)$, demand shocks influence the level of employment through the prediction error $\left(p-p^{a}\right)$.

Market for goods

Equations (3) and (4) being unchanged, we obtain from the expression of $n$ above:

$y=\frac{\alpha \rho\left(p-p^{a}\right)+\alpha d-\alpha \rho \xi \hat{t}}{1+\rho \theta}+c$ 
$\hat{i}=-\frac{\alpha\left(\rho\left(p-p^{a}\right)+d\right)}{\sigma(1+\rho \theta)}+\frac{\lambda}{\sigma}(\varphi g+a)+\left(\frac{\alpha \rho \xi}{\sigma(1+\rho \theta)}-\frac{\gamma}{\sigma}\right) \hat{t}-\frac{1}{\sigma} c$

Once more, the results diverge from those of the previous model only in case of inflationary surprise. Providing it is not expected, monetary policy recovers a stabilisation power.

Market for money

Using equation (5) in order to determine the behaviour of the price index, we get from the expression of $y$ above:

$$
p=\frac{1+\rho \theta}{1+\rho \theta+\alpha \rho}(m-c)+\frac{\alpha\left(\rho p^{a}-d\right)}{1+\rho \theta+\alpha \rho}+\frac{\alpha \rho \xi}{1+\rho \theta+\alpha \rho} \hat{t}, \text { for } p \neq p^{a}
$$

But in the long run, for $p=p^{a}$ and we get:

$$
p=m-c-\frac{\alpha}{1+\rho \theta} d+\frac{\alpha \rho \xi}{1+\rho \theta} \hat{t}
$$

Hence, as far as there are inflation surprises, money quantity variations no more transmit totally to the price index. Since variations in $y, w, n$ and $\hat{i}$ depend on the price index and therefore on the quantity of money, classical dichotomy seems to have disappeared. In addition, money does not work through the channel of interest ( $\sigma$, which measures the sensibility of aggregate demand to changes in the rate of interest, does not appear in $n$, neither does it in $y$ after having replaced $p$ ). Indeed, it is through unpredicted variations in the price index that variations in the quantity of money can have real effects, including the rate of interest.

A more sophisticated demand for money can be preferred so as to take risk into $\operatorname{account}^{10}$ :

$m=y+p-\eta \hat{i}$ 
It can easily be shown that the model globally has similar properties in this case, with the exception that interest channel works and government expenditures have real effects at equilibrium (provided that $p \neq p^{a}$, failing which the dichotomy reappears since employment and production are completely determined by the supply side equations (1'), (2") and (3)). The system therefore looks like an extended IS-LM framework (equations 4 and 5'), which contains a supply set of equations for endogenous determination of wages and prices (see the appendix $n^{\circ} 2$ ).

As Lavoie (2002) pointed out, in recent versions of the new consensus monetary policies consist in controlling the rate of interest rather than the quantity of money, which has to be considered as an endogenous variable. When the central bank controls $\hat{i}$, the LM function only determines the quantity of money that is equal to the demand for money, and therefore it is possible to solve the model for real magnitudes without it (cf. Romer, 2000) ${ }^{11}$.

\subsection{General equilibrium modelling in a Keynesian world}

Equation (5') admits different interpretations depending on the definition of uncertainty. In stochastic stationary regimes, risk makes money a useful portfolio diversification device, as we have just mentioned. This is a step towards the Keynesian monetary theory, but it does not capture its essential features. Indeed, there is a fundamental difference in the way to manage uncertainty when dynamic stability is not ensured, compared with a system where agents may predict the future without making systematic errors. The Keynesian concept of liquidity preference is not captured in equation (5'); the liquidity preference does not result from any optimal decision concerning risk and return, which could make sense in presumed 
stationary regimes but does not ensure that it is 'the best' solution in a Keynesian world. According to The General Theory (Ch. 12, s. 2), its magnitude results from the confidence level that people give to their expectations (whatever the distribution of probabilities they may make use of).

This Keynesian specificity will be formally underlined through considering $\eta_{k}$ as an exogenous variable that is subject to the kind of volatility that usually affects expectations:

$$
m=y+p-\eta_{k} \hat{i}
$$

When aggregate demand (like prices) decreases, the need for transaction-money falls, and the rate of interest decreases, rising the demand and the price of goods and moving the real wages towards their full employment level ${ }^{12}$. But, in Keynesian contexts, the magnitude of the decrease in interest rate (the so-called 'Keynes effect') and of any positive real balance effect (people do not want to hold idle cash balances and therefore increase the demand for goods) depends on speculative decisions concerning the demand for money, with the result that income and employment finally depend on the degree of confidence of the moment and its impact on the demand for money. At equilibrium, there are no competitive mechanisms which could move the economy towards any predetermined 'long run' solution.

\subsubsection{Markets articulation and Keynesian equilibrium}

\section{Labour market}

Contrary to the case where firms are ensured to sell their production whatever the level, demand for labour will not be determined here by equation (1'), but by equation (3), which gives the variation in labour that makes the better use of the technology for a given level of the demand for goods. 
Since the level of labour is fixed by the demand of firms, the supply side equation of the labour market must determine the equilibrium wage. In the Classical world, as well as in the NCM 'long run', nominal wages adjustment, together with the realbalance effect, drives the real wages so as to ensure equality between labour supply and demand. The 'invisible hand' simultaneously drives the rate of interest so as to ensure that aggregate demand absorbs the full-employment supply of good. In such a world, money only can induce short run 'noises', but in a Keynesian world, shifts of the speculative demand for money may keep the 'invisible hand' away from full employment. Hence, as far as nothing in these conditions ensures the equalization of equilibrium real wages and marginal disutility of labour attached to a given level of effective demand, equation (2"), which represents the second Classical postulate, must be abandoned.

How then has the equilibrium nominal wage to be determined? The General Theory discussion of the labour market pointed out that a decrease in wages does not systematically increase employment, because of the negative demand effects it may provoke through the expected return on capital. The existence of an equilibrium with under-employment means that the self-regulatory process failed, either the wages decrease have not been able to stimulate the effective demand or have amplified the depression (but in this case wages should continue to fall ${ }^{13}$ ), or workers have been able to stop the decrease in wages. We will therefore suppose that nominal wages are anchored in an exogenous (but variable) threshold $(\bar{w})$. The current wage however may deviate from this threshold when certain events occur, such as a change in unemployment rate or exogenous disturbances:

$w=\bar{w}-\theta_{k}\left(n_{f}-n\right)$

where $n_{f}$ is the rate of change of the labour force. 
Market for goods

Since the market equilibrium requires that firms adjust the production $(y)$ to the effective demand (equation 4) and technology then determines employment (equation 3), employment does not result from equation (1'). This does not mean that firms can not adjust the marginal productivity of labour to the factor real cost, but only that it is not through the employment level that they can do it. Equation (1') actually gives the price index variation that makes firms able to remain on their demand for labour curve, despite the fact that the demand for labour is constrained by the demand for goods. When demand increases, it is through inflation that the real wage variation is made equal to the marginal productivity decline, prompting firms to raise their production in order to respond to the increasing demand.

Without changing the formal condition expressed in equation (1'), we can rewrite it in accordance with the Keynesian approach to inflation:

$p=w+n-y-\dot{\alpha}+\xi \hat{t}$

where $-\dot{\alpha}+\xi \hat{t}$ is the rate of variation of the mark-up on unit labour $\operatorname{cost}^{14}$.

Inflation may be caused by interest rate variations through their impact on aggregate demand and output, but in contrast to the NCM model, this impact does not require inflation surprises. In addition, inflation reveals its connection with labour costs, including taxes, and with the mark-up. Equation (1") also indicates that a positive shift in output, which reduces the productivity of labour ${ }^{15}$, does not necessarily imply a decline of real wages; it depends on the mark-up behaviour. Thus real wages may vary pro-cyclically. 


\section{Market for money}

Following the post-Keynesian approach to endogenous money, we will suppose that banks deliver the quantity of money that is demanded at the current rate of interest, which is influenced by the central bank decisions. However, despite the formal resemblance, the functioning of the market differs from the NCM one, notably because of the speculative demand instability. Hence, the transmission of short-term interest rates variations, through which the central bank may influence the long-term interest rates, is made uncertain. For example, lower short-term rates (increases in high-powered money) aiming to extend credit do not produce the same decline in long-term rates depending on whether the liquidity preference changes or not. When it rises, banks may be able to sell more credit without having to reduce their interest rates, for non-bank loans rates in this case tend to rise in order to compensate the increasing liquidity preference. Moreover, speculative behaviours also may block the transmission process when the current rates are considered as very low (liquidity trap). Thus automatic monetary rules à la Taylor turn out to be excessively optimistic in a Keynesian context.

\subsubsection{Formal similarities and fundamental discrepancies}

From a formal point of view, the differences between the two models concern equations $\left(2_{\mathrm{k}}\right)$ and $(2 ")$, as long as LM is not explicitly represented. If, as usually supposed, the labour force is constant in the short run $\left(n_{f}=0\right)$, differences restrict to wages determinants $\left(\bar{w}\right.$ or $\left.p^{a}\right)$ and parameters $\left(\theta\right.$ or $\left.\theta_{k}\right)$ which have different definitions in the two models.

Thus, apart from the postulate that shocks $\left(c_{i}, \alpha_{i}, p_{i}{ }^{a}, a_{i}\right)$ are temporary deviations from a stationary regime in the NCM model, the short run behaviour modelling of 
non-ergodic systems seems very similar to the modelling of presumed stationary regimes with rational expectations. However, this formal similarity hides fundamental differences about the general equilibrium properties. First, the volatility of the demand for money (equation $5_{k}$ ) threatens the interest rate ability to push aggregate demand up to full employment at the union level (whatever way it might take, spontaneous competitive forces or monetary policy). Second, Keynesian equilibrium is driven by effective demand; there is no force of attraction towards any predetermined "long run" or "natural" position (in that sense, Keynesian equilibrium is not a temporary situation). Third, the fact that unemployment does not tend to reduce nominal wages beyond some exogenous limit is not a cause of unemployment; in certain circumstances, it can even be viewed as a protection against cumulative depressive forces (but a shift in unemployment may weaken the workers resistance, as in equation $2_{k}$ ).

Other fundamental discrepancies concern the signification of inflation and the role of monetary policy. We have mentioned the connection between cost pushed inflation and demand led inflation. Indeed, inflationary effects associated to wages, mark-up and/or tax pressures $\left(\bar{w}_{i}>0, \dot{\alpha}_{i}>0, \hat{t}_{i}>0\right)$ in equation (1'), depend on the way monetary authorities will pass them on effective demand. Inflation develops if the central bank satisfies the additional demand for money induced by cost pressures, in order for example to stabilize the rate of interest. If on the contrary monetary authorities aim to stabilize the price index, they do not prevent the rise of interest rates, so as to offset the inflationary effects of increasing costs through a depressive impact on effective demand. Hence, recurrent distributive conflicts, whatever the reason (wage-profit sharing, fiscal pressures), force monetary policy into dilemma: to accept the inflationary consequences and preserve economic activities, or to depress 
economic activity in order to stabilize the real value of money through a nontemporary pressure of unemployment on wages. In the Keynesian context, monetary policy is involved in the determination of equilibrium and income distribution; it is not a simple stabilization device for self-regulated systems.

\section{Alternative macro-governance approaches}

According to the NCM, debt monetization and willingness to get extra output are the primary causes of inflation. Solutions stem from governance principles like central bank independency and public deficit limitation, which aim to prevent central banks to create more money that needed for making transactions at current prices. Whereas such principles seem suitable in a stationary system, they can deteriorate the situation in the presence of Keynesian unemployment. This section compares the main implications of the NCM governance in both presumed stationary regimes and Keynesian regimes.

\subsection{NCM governance}

The type of governance that is suggested by the NCM is based on targets that are defined in relation to the expected trajectory of the economy. Temporary deviations of the rate of interest may be decided for stabilization purposes, in such a way that the quantity of money evolves in concert with the demand induced by the economic growth, without inflation pressures. Conversely, policies that aim systematically to get extra output through inflation surprise or debt monetization are fully predictable and therefore inefficient; they only feed the inflation core. Consequently, the new consensus pleads in favour of central bank political independence and low inflation targeting. In addition, according to the 'unpleasant monetarist arithmetic' that Sargent 
\& Wallace [1981] pointed out, public deficit limitations are necessary for the credibility and efficiency of monetary policy.

3.1.1. Modelling macroeconomic governance within the new synthesis vision of the world

In order to draw some analytical conclusions from the model, let us assume that credible institutions ensure there is no inflation bias, so that active monetary policy only aims to stabilize the system by means of (non-systematic) inflation surprise $\left(p \neq p^{a}\right)^{16}$. Since the central bank is credible, private agents anchor their expectation on the announced inflation target. However, in front of a shock, authorities deviate from the target in order to stabilize employment, with a magnitude which depends on their degree of 'Conservatism' about inflation.

Fiscal authorities for their part have a budget balance target related to their financial policy and debt management constraints. As well as monetary authorities, they concede temporary deviations according to their degree of 'Orthodoxy'.

The appendix $n^{\circ} 2$ (case b) shows that in the model of endogenous money, monetary, budgetary and fiscal instruments $(\hat{i}, g, \hat{t})$ influence the equilibrium value of output, employment and prices. Hence they influence also the budget balance $(b$, see the appendix $\left.n^{\circ} 3\right)$ :

$b=\varphi(y-g)+\hat{t}$

We suppose that the deviations of instruments are decided with respect to employment deviations. The short run objectives will be:

$$
\begin{aligned}
& b=\psi n \\
& p=-\beta n
\end{aligned}
$$


Equation (8) for example means that, in order to stabilize the economic activity, a positive (negative) temporary deviation of the price index is accepted in case of a negative (positive) deviation from the natural rate of employment. Parameters $\beta \geq 0$ and $\psi \geq 0$ represent respectively the monetary 'Conservatism' and the fiscal 'Orthodoxy'. $\beta=0$ means that there are no short run deviations from the inflation target (full 'Conservatism'). $\psi=0$ means that the budget deficit (or surplus) depends only on financial long run considerations, and do not participate in stabilization operations.

This way of modelling policy rules simplifies algebra, but it is consistent with the usual loss-function minimisation procedure ${ }^{17}$.

Starting from equations (1"), (2"), (3) and (4), and provided that the government changes expenditures for example, rather than taxes, in order to reach its objective, we get:

$$
\begin{aligned}
g= & \frac{\psi-\varphi \alpha}{\varphi(\beta+\theta+1-\alpha)}\left(p^{a}-\dot{\alpha}\right)+\frac{\varphi(\beta+\theta+1)-\psi}{\varphi(\beta+\theta+1-\alpha)} c+\frac{\beta+\theta+1-\alpha+(\psi-\varphi \alpha) \xi}{\varphi(\beta+\theta+1-\alpha)} \hat{t} \\
b= & -\psi \frac{p^{a}-\dot{\alpha}-c+\xi \hat{t}}{\beta+\theta+1-\alpha} \\
\hat{i}= & \frac{\lambda}{\sigma} a-\frac{\lambda \psi+(1-\lambda \varphi)(\beta+\theta+1)}{\sigma(\beta+\theta+1-\alpha)} c+\frac{\lambda \psi-\lambda \varphi \alpha+\alpha}{\sigma(\beta+\theta+1-\alpha)}\left(p^{a}-\dot{\alpha}\right) \\
& +\frac{(\lambda-\gamma)(\beta+\theta+1-\alpha)+(\lambda \psi-\lambda \varphi \alpha+\alpha) \xi}{\sigma(\beta+\theta+1-\alpha)} \hat{t}
\end{aligned}
$$

Public expenditures only respond to supply shocks, and if necessary to fiscal changes. The reason is that monetary policy neutralizes the effects of demand shocks on output and prices, as the solutions attest:

$$
\begin{aligned}
& n=-\frac{p^{a}-\dot{\alpha}-c+\xi \hat{t}}{\beta+\theta+1-\alpha} \\
& y=\frac{(\beta+\theta+1) c-\alpha\left(p^{a}-\dot{\alpha}+\xi \hat{t}\right)}{\beta+\theta+1-\alpha}
\end{aligned}
$$


$p=\beta \frac{p^{a}-\dot{\alpha}-c+\xi \hat{t}}{\beta+\theta+1-\alpha}$

with the result that government reaches its objective without having to move its instrument, since employment and fiscal revenues remain unchanged.

Finally, because they work through aggregate demand channels, public expenditures and interest rate reactions protect the economy against demand shocks, but only yield imperfect management of supply shocks. It is of interest to note that temporary changes of the fiscal distortion level can usefully improve the policy mix, since they make possible to cancel the effects of the shocks on prices and employment without budget balance deterioration:

$\hat{t}=\frac{c+\dot{\alpha}-p^{a}}{\xi} \Rightarrow p=n=b=0$

That is the reason why deficits limitations are not really considered by the NCM as obstacles to stabilization.

\subsubsection{New governance in a Keynesian world}

What kind of consequences may have such governance principles in a Keynesian situation of unemployment? In order to answer the question, let the exogenous variable $q$ represent the variation in employment that is initially required for full employment. Since $n$ is the variation in employment for the current period, $q-n$ measures the level of unemployment at the end of the period. As authorities think that $q$ reflects the natural rate of unemployment $(\bar{w}, c, \dot{\alpha}$, and $a$ are supposed to provoke temporary deviations from the trajectory), they do not take it as a stabilization matter, and make the policy discussed in Section 3.1.1.

The formal results of the previous section can be easily adapted to the present configuration when the labour force remains unchanged during the current period 
$\left(n_{f}=0\right)$, provided we replace equation $(2 ")$ by equation $\left(2_{\mathrm{k}}\right)$, which only supposes that $\bar{w}$ and $\theta_{k}$ replace $p^{a}$ and $\theta$ ). It follows that, in the most favourable case where authorities can completely stabilize the price index and the activity level without budget balance deterioration, unemployment remains blocked at its initial level ( $q$ $n=q$ ). Thus, as long as the actual level of unemployment is the target level, the policy mix tends to perpetuate unemployment.

In less favourable cases, authorities have not enough room for manoeuvre in terms of taxes-expenditures capacity of adjustment and interest rate control, with the result that effective demand depressions can not be offset totally. The problem is all the more serious since Keynesian unemployment does not tend spontaneously towards any predetermined 'long run value', contrary to what authorities think, with the result that they take the new rate of unemployment as the new natural one. That suggests a different explanation of what New Keynesians have referred to as unemployment hysteresis $^{18}$ : restricted policy-mix reactions to effective demand depressions only weaken the rise of unemployment, but subsequently neither market forces nor economic policy tends to restore the initial level. Actually, as far as wages respond to the variations in unemployment, not to its level, the NCM concludes to real wages rigidity, hiding by the way what in fact is a lack of policy mix flexibility (remember that wage flexibility does not ensure better results in the Keynesian thought).

Things may even be worsen when recurrent distributive tensions exist, because the central bank tends to raise the rate of interest according to the conflict intensity. Indeed, as long as persistent inflationary pressures are interpreted as the result of a 'natural' lower demand for money (provided the supply did not rise), monetary policy takes a harder line and becomes a depressive force. 
Thus, despite the fact that the two theoretical approaches share the same objectives in the field of macroeconomic governance (that is full employment, prices stability and sound public finance), stationary-regime designed governance may be singularly inappropriate in a Keynesian world.

\subsection{Keynesian macroeconomic governance}

Controlling inflation

Even though inflation always comes from a gap between the money supply and the demand for money expressed at current prices, it is instructive to consider the causes of the gap. For example, according to the real balance effect, a decrease in effective demand may produce inflation insofar as it reduces the demand for money. This is quite different from surprise inflation or seigniorage; it takes part in the adjustment process towards equilibrium. It develops especially when wages rigidity impedes the adjustment of real wages. It would be strange if monetary policy aimed to fight inflation after a demand depression when wages are rigid. Central banks rather tend to decrease interest rates in such cases, so as to facilitate the adjustment. New and old Keynesians could agree on this, despite the former consider effective demand failures as temporary shocks.

Another source of inflation is the conflict about income distribution. Mainstream economics interprets distributive tensions in terms of stochastic supply shocks or in terms of structural change (if they are recurrent), never as a moving compromise which interacts with other economic decisions. Insofar as, by assumption, economic agents may freely adjust their plan to the perceived market real prices, a disagreement about nominal earnings, given expected future prices, takes the form of a supply-cut at current prices. That comes to an increase in the natural rate of 
unemployment. If the central bank aims to smooth the depressive effects on output, it can be driven to temporarily create money, so as to compensate the supplementary need for transaction money which is induced by (temporary) tensions. But, in the long run, monetary policy can not avoid the depressive effects of negative supply shocks. As concerns recurrent (then foreseeable) pressures, the central bank could not repetitively smooth the negative effects on the supply side, because recurrent inflationary measures would be expected, and therefore would not deliver real effects.

The Keynesian point of view about this question is quite different, even though the results are similar. First, section 2.2.2 showed that in the presence of recurrent distributive tensions, low inflation targeting may introduce a deflationary bias into monetary policy, with non-temporary higher unemployment, what contrasts with the neutrality of money in the NCM "long run". In addition, when strong tensions compel the central bank to restrict monetary policy, high unemployment may drive the governments to accept high deficits in a context of high interest rates. On the contrary, safe distributive conditions help monetary policy to contain interest rates and to contribute to the policy mix efficiency (see below).

Hence, monetary policy is not always the unique way, nor is it the best, to control inflation; legal and institutional rules concerning income distribution play a crucial role as well. Actually, the two aspects should not be considered separately.

Inflation control raises additional problems in monetary unions, for the same monetary policy applies in all member countries, regardless of where inflationary pressures started. Furthermore, interest rate interactions with national budgetaryfiscal policies have to be taken into account. The following section discusses this point. 


\subsubsection{Governing according to the context}

In non-ergodic systems, macroeconomic governance should not hinge on mechanic rules whose consequences are supposed being well known and able to reach

predefined targets. It is always possible to have ideal objectives, but it is not always reasonable to make it the short run target of a policy mix because economic policy may spark changes in expectations and private economic decisions, which may in turn make the policy inappropriate (as popularized the Lucas critique) ${ }^{19}$. Keynesian context requires pragmatic governance, which goes through intermediate targets in order to avoid jolts that could destabilize private expectations and decisions.

Formally, such an approach suggests replacing equation (7), which fixed the government objective in the NCM model, by a condition of the type:

$n=\mu q$

$0<\mu \leq 1$

where $\mu$ is a parameter that the government chooses in function of the confidence he has in the success of operations. It is important to bear in mind that this equation, like most equations of Keynesian models, does not pretend to the stability that is usually assumed. Indeed $\mu$ is subject to various changing factors. Some of them concern the effective demand expected sensitivity to the policy instruments; others depend on financial constraints which may limit the government room for manoeuvre, others may add political considerations (e.g. public opinion)... In this perspective, economic-policy designing hinges as much on the selection of the objective (value of $\mu$ ) as on the adjustment of instruments (value of $g$ or $\hat{t}$ which solves equation (9), given equations (1"), $\left(2_{\mathrm{k}}\right),(3)$ and (4)).

Nevertheless, since the budget balance depends on the short run employment objective, the government may have to limit the increase in public expenditures, 
unless it is able to adjust taxes. Consequently, employment and budget balance objectives, as well as the concerned instruments, turn out to be interdependent, and therefore must be simultaneously chosen. Hence, let us suppose that the budgetbalance target depends more or less on the magnitude of unemployment (according to the room for manoeuvre of the period and to the relative importance the government gives to employment...):

$b=-\psi_{k}(q-n)+z$

where $\psi_{k} \geq 0$ represents the 'fiscal flexibility' (the higher $\psi_{k}$ is, the less the government adjusts taxes, and the higher is the deficit), and $z$ represents other factors which may interfere in the short run, like deliberate structural deficit due to long run public investments or debt management considerations. Once again, the problem as much concerns the selection of the objective (value of $\psi_{k}$ ) as the adjustment of instrument (value of $\hat{t}$ or $g$ which solves equation (10)).

It is then possible to determine the pair $(g, \hat{t})$ which solves conditions (9) and (10), given equations (1"), ( $2 \mathrm{k}),(3)$ and (4):

$$
\begin{aligned}
& g=\frac{\alpha \mu(1-\gamma \varphi)-\gamma \psi_{k}(1-\mu)}{\varphi(\lambda-\gamma)} q+\frac{\gamma}{\varphi(\lambda-\gamma)} z-\frac{\lambda}{\varphi(\lambda-\gamma)} a+\frac{1-\gamma \varphi}{\varphi(\lambda-\gamma)} c+\frac{\sigma}{\varphi(\lambda-\gamma)} \hat{i} \\
& \hat{t}=\frac{\alpha \mu(1-\lambda \varphi)-\lambda \psi_{k}(1-\mu)}{\lambda-\gamma} q+\frac{\lambda}{\lambda-\gamma}(z-a)+\frac{1-\lambda \varphi}{\lambda-\gamma} c+\frac{\sigma}{\lambda-\gamma} \hat{i}
\end{aligned}
$$

Within this framework, budgetary and fiscal policy works as a flexible anchor around full employment (since $\mu$ may vary). Actually, because of effective demand and employment sensitivity to the interest rate, the move of instruments required by conditions (9) and (10) depends on the monetary policy. Of course interest rates also matter for the choice of objectives $\left(\mu_{i}, \psi_{k i}\right)$. For example, if the government thinks that the central bank will accommodate, it can adopt a more ambitious plan. Thus, the central bank can make it more or less difficult for the government to reach the 
objectives. Notice that central bank participation to economic recovery does not absolutely necessitate lower interest rates. Remember that $\hat{i}=0$, for example, means that banks adjust the supply of money to the demand expressed at the unchanged rate of interest. Thus, even when the central bank can not significantly reduce the interest rates (if, for example, they are already very low), it can help in a decisive way by controlling the monetary tensions that economic recovery usually provokes.

\section{Conclusion}

Modelling the NCM and Keynesian approaches of competitive economies within the usual four-macro-markets representation reveals some key sources of divergence. In particular, Keynesian uncertainty plays a crucial role through speculative money demand instability and interest rate adjustment, and through the leadership of effective demand. Hence market interactions differ, with the result that the optimumoriented competitive forces work in ergodic regimes, not in the Keynesian representation of the world.

Because the NCM governance was designed for efficient stationary systems, it carries several drawbacks when implemented in Keynesian non-ergodic systems. In the presence of Keynesian unemployment, as long as actual unemployment and interest rates are interpreted as 'natural' rates, they serve as macroeconomic policy targets, in such a way that the policy mix may anchor the system away from full employment. The situation persists for it seems to be the consequence of real wages rigidity. Our argument suggests a Keynesian explanation (which involves inappropriate economic policy) of what New Keynesians have referred to as unemployment hysteresis. Things may even be made worse by distributive tensions, because the rate of interest tends to rise according to the conflict intensity. Indeed, 
since inflationary pressures are interpreted as the result of a 'natural' lower demand for money (provided the supply did not rise), monetary policy takes a harder line and becomes a depressive force.

Unfortunately, difficulties do not vanish when authorities adopt the Keynesian vision of the world. For example, as regards inflation control, recurrent distributive tensions force monetary policy into dilemma: to accept the inflationary consequences and preserve economic activities, or to depress economic activity in order to preserve the real value of money through permanent unemployment pressure on wages. From this point of view, legal and institutional rules concerning the distribution of income reveals to be of primary importance, which corroborates the idea that economic efficiency at the macro level, far from being the automatic outcome of free competitive forces, should not be considered independently of the political and social context.

Governance principles in accordance with the non-ergodic approach have been explored in the last part of the paper. In contrast with the automatic policy rules of the NCM, we put forward a pragmatic and progressive approach to macroeconomic policy that avoids destabilizing expectations and private decisions. In such a framework, authorities fix intermediate reasonable targets with respect to the confidence they have in the chance of success, which depends on the actual context and moves with it. In our simplified modelling, the taxes-expenditures combination that is required to reach employment and budgetary targets depends on a set of variables and parameters that represent the macroeconomic changing context and the confidence of authorities. This set of variables of course contains the rate of interest, which expresses the monetary influences on the policy mix. Monetary policy modelling is very sensitive in a Keynesian world because the control of long term 
rate of interest is uncertain, at least as far as reductions are concerned; but even when its positive influence on effective demand is doubtful, it matters indirectly through avoiding increases in interest rates when fiscal and budgetary policy aims to stimulate effective demand.

\section{Appendix n ${ }^{\circ} 1$}

Starting from the aggregate demand function $v(Y-t Y)-\beta\left(i-p_{+1}^{a}\right)+G+A$, where $Y$ represents the output volume, $i$ the rate of interest, $p^{a}{ }_{+1}$ the expected inflation rate till the next period, $t$ the tax rate (taxes/output), $v$ the propensity to consume, $G$ the governments expenditures, $A$ an autonomous component, the market for goods equilibrium requires: $Y=v(Y-t Y)-\beta\left(i-p_{+1}^{a}\right)+G+A$.

Differentiating around a solution indexed by 0 (with $d v=0$ and $d p^{a}{ }_{+1}=0$ ), and dividing by $Y_{0}$, we get:

$\frac{d Y}{Y_{0}}=v \frac{d Y}{Y_{0}}-v t_{0} \frac{d Y}{Y_{0}}-v d t-\frac{\beta}{Y_{0}} d i+\frac{d G}{Y_{0}}+\frac{d A}{Y_{0}}$

Since $t_{0}=T_{0} / Y_{0}$, the equality $d G / Y_{0}=t_{0} d G / G$ o holds when the budget is balanced

$\left(T_{0}=G_{0}\right)$. Writing relative deviation rates with small letters $\left(x=d X / X_{0}\right)$, except $a=d A / Y_{0}$, we have:

$y=v\left(1-t_{0}\right) y-v d t-\frac{\beta}{Y_{0}} d i+t_{0} g+a$

hence:

$y=-\sigma \hat{i}+\lambda(\varphi g+a)-\gamma \hat{t}$ 
where $\hat{i}=d i, \hat{t}=d t, \varphi=t_{0}, \gamma=\frac{v}{1-v\left(1-t_{0}\right)}, \lambda=\frac{1}{1-v\left(1-t_{0}\right)}, \sigma=\frac{1}{1-v\left(1-t_{0}\right)} \frac{\beta}{Y_{0}}$

\section{Appendix $n^{\circ} 2$}

a) The model lends itself to an analysis in terms of aggregate supply and aggregate demand. Equations (4) and (5') give the demand equation $y(p)$, which may be written as $p(y)$ :

$$
p=\frac{-(\eta+\sigma) y+\eta \lambda(\varphi g+a)-\eta \gamma \hat{t}}{\sigma}+m
$$

Equations (1'), (2"), and (3) give the supply equation:

$$
y=\frac{\alpha \rho\left(p-p^{a}\right)+\alpha d-\alpha \rho \xi \hat{t}}{1+\rho \theta}+c
$$

Resolution yields $y$ and $p$, which permits to solve for $n$ by (3), then $w$ by (2"), and finally $\hat{i}$ by $\left(5^{\prime}\right)$. Remember that output variations do not really depend on current price index variations, but on the current price index error of prediction, as the supply equation shows.

b) When monetary authorities control the rate of interest and adjust the quantity of money to the demand, output $(y)$ is determined by the sole aggregate demand components (equation 4). We get $n$ by (3), then $w$ by (2") and finally $p$ by (1'):

$$
\begin{aligned}
& y=-\sigma \hat{i}+\lambda(\varphi g+a)-\gamma \hat{t} \\
& n=\frac{\lambda(\varphi g+a)-c-\sigma \hat{i}-\gamma \hat{t}}{\alpha} \\
& w=p^{a}+\frac{\lambda \theta(\varphi g+a)-\theta c-\sigma \theta \hat{i}-\gamma \theta \hat{t}}{\alpha} \\
& p=p^{a}+\frac{\lambda(1+\rho \theta)}{\alpha \rho} a-\frac{\gamma(1+\rho \theta)-\alpha \rho \xi}{\alpha \rho} \hat{t}-\frac{1+\rho \theta}{\alpha \rho} c+\frac{\lambda \varphi(1+\rho \theta)}{\alpha \rho} g-\frac{\sigma(1+\rho \theta)}{\alpha \rho} \hat{i}-\frac{d}{\rho}
\end{aligned}
$$

Output variations here depend on the rate of interest, but it can easily be shown that 
if it is set so as to avoid any price index error of prediction $\left(p=p^{a}\right)$, then the results are the same as in the case of exogenous money supply where $m$ is set so as to avoid errors of prediction.

Appendix $n^{\circ} 3$

The budget balance $(B)$ is defined as:

$B=t P Y-P G$

Differentiating around a solution indexed by 0 yields:

$d B=t_{0} P_{0} d Y+P_{0} Y_{0} d t+t_{0} Y_{0} d P-P_{0} d G-G_{0} d P$

and dividing by the initial value of output:

$d B /\left(P_{0} Y_{0}\right)=t_{0} d Y / Y_{0}+d t+t_{0} d P / P_{0^{-}} d G / Y_{0^{-}}\left(G_{0} / Y_{0}\right)\left(d P / P_{0}\right)$

Hence, around a situation of balanced budget where $t_{0}=G_{0} / Y_{0}\left(\right.$ remember $\left.g=d G / G_{0}\right)$ :

$b=t_{0}(y-g)+d t$

and, with the same notation as in appendix $n^{\circ} 1$ :

$b=\varphi(y-g)+\hat{t}$

Notes

1 This kind of policy aims to maintain the rate of unemployment below the natural rate. It differs from occasional (not expected) policies, which may have temporary impact on economic activities because of inertia of wages (see below).

2 This may occur because of the overcrowding of installed capacity and the lack of some skills of labour and goods (including capital goods) in some industries.

3 The system may jump from a trajectory to another, when the regime changes. 
4 See the discussion of the relation between inflation targeting and the NCM in Arestis \& Sawyer (2003a).

5 See Arestis and Sawyer (2003b).

6 The short run we are discussing now is the one for which capital stock and productive capacity may approximately be considered as constants. It is different from the 'short run' mentioned in the introduction.

7 Had the model an additional market for money, there would have been a third relative price (the price of money in terms of goods: $1 / p$ ). As we know, in such a system real prices and other real variables are independent of money (which only accounts for nominal variables and prices; see below).

8 See the appendix $n^{\circ} 1$.

9 This point supposes that competitive mechanisms anchor the system in a predetermined trajectory. It has been identified as the dynamic stability of a stochastic process (ergodicity). See Vercelli (1991) pp. 40, 154, and Davidson (2002) pp.39, 69.

10 Following Tobin (1958), money helps to diversify portfolios in order to optimize the return / risk ratio (the higher the rate of interest, the more one is encouraged to increase the proportion of risked assets, and to reduce the proportion of money). 11 See the case b) of the appendix n ${ }^{\circ} 2$. As stated Palley (2006), this assessment of endogenous money substantially differs from the post-Keynesian one.

12 Theoretically, it is possible that flexible nominal wages reach this solution without any variation in the rate of interest (but it is not certain; see The General Theory, Ch. 19): through positive effects on the marginal efficiency of capital and effective demand, wage flexibility may produce inflation, reduce real wage and rise 
production. If on the other hand nominal wages are sticky, the role of interest rate becomes crucial.

13 See Tobin (1975) and Palley (2005) about this kind of instability.

14 It is not essential to make imperfect competition assumptions in order to obtain a mark-up relation. For example, starting with the production function $Y=C N^{\alpha}, \alpha<1$, competitive pricing requires the marginal productivity to be equal to the real cost of labour: $\partial Y / \partial N=W(1+\xi t) / P \Rightarrow P=W(1+\xi t) /\left(C \alpha N^{\alpha-1}\right)=(W N(1+\xi t) / Y) / \alpha$; hence, by differentiation of the associated logarithmic expression (for small values of $\hat{t}$ ), we have $p=w+n-y-\dot{\alpha}+\xi \hat{t}$, where $\dot{\alpha}$ is the rate of variation in $\alpha$ (exogenous). Notice that an increasing mark-up on unit labour cost expresses in this case a declining wages-output ratio $(\dot{\alpha}<0)$ and/or increasing fiscal taxes $(\hat{t}=d t>0)$. 15 From equation (3), we have: $y-n=(\alpha-1) n+c$. Hence, an increase in effective demand and employment reduces the productivity of labour (that is $c$ constant), and rises the unit cost of production. This shows that cost pushed inflation and demand led inflation may express the same reality. In fact, whatever apparent causes it has, inflation always requires an increase in demand (see below, Section 2.2.2).

16 According to the no-inflation-bias hypothesis we should have in general $p^{a}=0$, but it may be useful to conserve this variable as an exogenous temporary shocks on expected inflation.

17 For example, the first order condition that $g$ must verify in order to minimize $L=(1 / 2)\left(\varsigma n^{2}+b^{2}\right)$ is $\varsigma n(\partial n / \partial g)+b(\partial b / \partial g)=0$, which is equivalent to $b=\psi n$ provided that $\psi=-\varsigma(\partial n / \partial g) /(\partial b / \partial g)$. This approach sometimes raises difficulties that will not be discussed here.

18 On hysteresis, ergodic and non-ergodic regimes, see the Minisymposium in the Journal of Post Keynesian Economics, 15(3), Spring 1993. 
19 Keynes raised the question in The General Theory (Ch. 15, see the last third of Section II). Of course, the meaning and implications considerably differ owing to the methodological opposition (see Vercelli, 1991).

\section{References}

P. Arestis and M. Sawyer, 'Inflation targeting: a critical appraisal', The Levy

Economics Institute working papers, $\mathrm{n}^{\circ} 388$ (2003a).

P. Arestis and M. Sawyer, 'Reinventing fiscal policy', Journal of Post-Keynesian Economics, 26(1) (2003b) 3-26.

P. Davidson, Financial markets, money and the real world (Cheltenham: Edward Elgar, 2002).

C. Freedman, G. C. Harcourt and P. Kriesler, 'Has the long-run Phillips curve turned horizontal?', in G. Argyrous, M. Forstater and G. Mongiovi (eds), Growth, Distribution and Effective Demand: Alternatives to Economic Orthodoxy (Armonk: M.E. Sharpe, 2004), pp. 144-162.

P. Kriesler and M. Lavoie, 'The new view on monetary policy: the new consensus and its post-Keynesian critique', unpublished paper, available on the internet, Marc Lavoie's Homepage (2005).

M. Lavoie, 'A post-Keynesian alternative to the New consensus on monetary policy', paper presented at the ADEK conference, CEMF, Université de Bourgogne, Dijon, 2002.

A. Palacio-Vera, 'The "modern" view of macroeconomics: some critical reflections', Cambridge Journal of Economics, 29(5) (2005), 747-67. 
T. I. Palley, 'Keynesian Models of Recession and Depression', unpublished manuscript, november 2005, available at the author website:

www.thomaspalley.com.

T. I. Palley, 'A Post Keynesian Framework for Monetary Policy: Why Interest Rate Operating Procedures are not Enough', in C. Gnos and L.-P. Rochon (eds), Post Keynesian Principles of Economic Policy, (Cheltenham: Edward Elgar, 2006).

D. Romer, 'Keynesian macroeconomics without the LM curve', Journal of Economic Perspectives, 14(2) (2000) 149-169.

T. Sargent, N. Wallace, 'Some unpleasant monetarist arithmetic', Federal reserve bank of Minneapolis Quarterly Review, Fall (1981) 1-17.

J. Tobin, 'Liquidity preference as behaviour towards risk', Review of Economic Studies, 25 (1958), 65-86.

J. Tobin, 'Keynesian Models of Recession and Depression', American Economic Review, 65 (1975), 195-202.

A. Vercelli, Methodological foundations of macroeconomics: Keynes and Lucas (Cambridge: Cambridge University Press, 1991). 